\title{
Contribution to the marine propeller hydrodynamic design for small boats in the Amazon region
}

\author{
Breno Inglis FAVACHO ${ }^{1}$, Jerson Rogério Pinheiro VAZ ${ }^{*}$, André Luiz Amarante MESQUITA ${ }^{1}$, Fábio LOPES ${ }^{1}$, \\ Antonio Luciano Seabra MOREIRA ${ }^{1}$, Newton Sure SOEIRO ${ }^{1}$, Otávio Fernandes Lima da ROCHA ${ }^{2}$ \\ 1 Universidade Federal do Pará - Instituto de Tecnologia, Faculdade de Engenharia Mecânica, Av. Augusto Correa, N 1 - Belém, Pará, Brasil. \\ 2 Instituto Federal de Educação, Ciência e Tecnologia do Pará, Av. Almirante Barroso, N 1155 - Belém, Pará, Brasil. \\ * Corresponding author: jerson@ufpa.br
}

\begin{abstract}
In the Amazon, river navigation is very important due to the length of navigable rivers and the lack of alternative road networks. Boats usually operate in unfavorable conditions, since there is no hydrodynamic relation among propellers, geometry, and the dimensions of the boat hull. Currently, there is no methodology for propeller hydrodynamic optimization with low computational cost and easy implementation in the region. The aim of this work was to develop a mathematical approach for marine propeller design applied to boats typically found on Amazon rivers. We developed an optimized formulation for the chord and pitch angle distributions, taking into account the classical model of Glauert. A theoretical analysis for the thrust and torque relationships on an annular control volume was performed. The mathematical model used was based on the Blade Element Momentum Theory (BEMT). We concluded that the new methodology proposed in this work demonstrates a good physical behavior when compared with the theory of Glauert and the experimental data of the Wageningen B3-50 propeller. KEYWORDS: Optimization, BEMT model, theory of Glauert, Wageningen B3-50.
\end{abstract}

\section{Contribuição ao projeto hidrodinâmico de propulsores marítimos voltados as pequenas embarcações da região Amazônica}

\section{RESUMO}

$\mathrm{Na}$ Amazônia, a navegação é muito importante devido a extensão de rios navegáveis e a falta de redes rodoviárias alternativas. As embarcaçôes geralmente trabalham em condiçôes desfavoráveis, uma vez que não há relação entre a hidrodinâmica dos hélices, geometria e as dimensões do casco da embarcação. Atualmente, não há metodologia para otimização hidrodinâmica com baixo custo computacional e fácil implementação na região. O objetivo deste trabalho foi o desenvolvimento de uma abordagem matemática voltada para o projeto de propulsores marítimos aplicados as embarcaçóes tipicamente encontradas nos rios da Amazônia. Nós desenvolvemos uma formulação otimizada para o cálculo das distribuiçóes de corda e ângulo de torção, considerando o modelo clássico de Glauert. Uma análise teórica para as relaçóes de empuxo e torque em um volume de controle anular foi realizado. O modelo matemático utilizado foi baseado na teoria do momento do elemento de pá (BEMT). Concluímos que a nova metodologia, proposta neste trabalho, demonstra bom comportamento físico quando comparado com a teoria de Glauert e os dados experimentais do propulsor Wageningen B3-50.

PALAVRAS-CHAVE: Otimizaçáo, modelo BEMT, Teoria de Glauert, Wageningen B3-50. 


\section{INTRODUCTION}

The Amazon is the largest navigable river of the world, as well as the longest in length and largest in water flow (Costa 2004). The landscape competes with human occupation along the riverbeds, with navigation being the main means of transportation. The small, medium and large wooden boats constructed by builders in regional workshops are normally located at the riverside. Such boat builders use their own expertise, and although they do not follow the basic principles of marine engineering, this technology allow them to construct robust boats for the region. The most common problems found in boats of the region are the lack of technical procedures for the propellers' hydrodynamic design, and travel interruption due to damage of propellers. Thus, it is very important to develop new studies in order to search, for instance, for an efficient design of marine propellers aiming to present feasible and alternative methodologies which can be implemented in the Amazon context.

Propeller blade design is a complex process, since it is necessary to consider the influence of viscous flow around propellers and the effect of cavitation (Morgut and Nobile 2012; Zhu 2015). Although theoretical techniques are more consistent in relation to the precision of the propeller design, they are quite difficult to develop (Takinaci and Atlar 2002; Sánchez-Caja et al. 2014). Nevertheless, nowadays marine propellers are routinely designed with 3-dimensional theories based on Vortex Theory (VT) or Boundary Element Methods (BEM). However, such techniques require sophisticated computational procedures, are expensive, and they are not easily implemented in remote areas. Hence, the aim of this work was to develop a mathematical approach for marine propeller design applied to boats typically found on Amazon rivers, using an optimized formulation for the chord and pitch angle distributions, taking into account the classical model (Glauert 1935). For that, a theoretical analysis for the thrust and torque relationships on an annular control volume was performed, which was based on the Blade Element Momentum Theory (BEMT), in order to reach a propeller more efficient than those conventionally available.

\section{MATERIALS AND METHODS}

\section{Boat Survey of the Region}

In order to obtain a more effective, state of the art contribution to marine propellers in the Amazon region, a technical questionnaire was carried out with the owners of boats and workshops where the investigated propellers are produced. The survey was conducted in several towns of Pará State, where boats are made with wooden hulls, and have small dimensions requiring small propellers. Eighty interviews in total were performed, including fifty-four with users and twenty-six with producers. Most of the foundry workshops in the towns were visited. The document contemplated information on the boats' specifications (average speed, length of the waterline, number of passengers and crew members, quantity of cargo), the marine motor (brand, model, nominal power, rpm), and the propeller (geometrical settings, diameter, number of blades, diameter of the cube, dimensioning criterion). During the production process of these propellers, some hydrodynamic limitations were noticed which cause socio-economic damage, such as travel delay/interruption, increase in the costs of maintenance and operation, and navigation limitations. The data collected shows many kinds of propellers, dimensions, number of blades, pitch, shapes, and geometrical characteristics of the blades, due to the lack of engineering knowledge of builders. There is no hydrodynamic relation among propellers, geometry, and the dimensions of the boat hull, as well as other parameters involved. The lack of normative criteria of dimensioning and usage compromises partially or totally the system of propulsion and boat performance. Such factors impose serious limitations on hydrodynamic efficiency; consequently, boats endure premature wear of mobile parts, as well as unexpected stops for repairs, mechanical vibrations, motor overheating, and various other damages for both boat owners and users.

\section{Mathematical Model for the Propeller Hydrodynamic Design}

A methodology is described where the mathematical formulations for the propeller hydrodynamic design is based on the classical BEMT method (Bontempo et al. 2014). BEMT is a widely used approach for the analysis and design of propellers. Combining the basic principles from both blade element and momentum theories, it is inherently steady, two dimensional, stems from the equivalence between the circulation and momentum theories of lift, and allows the estimation of the inflow distribution along the blade. The present methodology shows that it is possible to determine the optimal geometry of a propeller using BEMT. For this, it is necessary to understand the physical principle of marine propeller operation, which is based on creating a fluid stream in the opposite direction to the vessel's movement, and whose impulse is able to overcome the forces of resistance imposed by the fluid, on the vessel. Thus, it considers a propeller able to transfer energy to the flow behind the propeller plane. Figure 1 shows the streamlines and the control volume for the theoretical propeller case. The velocities $\mathrm{V}, \mathrm{V}_{1}$ and $\mathrm{V}_{2}$ are the flow velocities at the propeller plane and in the wake, respectively. 
According to the classical references (Glauert 1935; Rankine 1865; Froude 1878), the local efficiency of the propeller is a function of the effective pitch angle, $\phi$. The local efficiency is defined only on the blade section, which sweeps out the annular ring shown in Figure 1.

$$
\eta=\frac{1-a^{\prime}}{1+a} \frac{\tan \phi}{\tan (\phi+\varepsilon)}
$$

Axial and tangential interference $a$ and $a$, respectively are dependent on $\phi$. The viscous effect is computed by $\varepsilon \approx \tan \varepsilon$ $=C_{D} / C_{L}$, where $C_{D}$ and $C_{L}$ are the drag and lift coefficients.

$$
\begin{aligned}
\frac{a}{1+a} & =\frac{s \lambda_{1}}{2[1-\cos (2 \phi)] F} \\
\frac{a^{\prime}}{1-a^{\prime}} & =\frac{s \lambda_{2}}{2 \sin (2 \phi) F}
\end{aligned}
$$

$s$ is the propeller solidity, and is defined by:

$$
s=\frac{N c}{2 \pi r}
$$

$N$ is the number of blades, and $c$ is the chord length at each blade section. $F$ is the Prandtl tip-loss model, which is an approximate solution for the potential flow around a set of translating helicoidal surfaces by liking the flow around the edges to the flow around a two-dimensional set of equally spaced semi-infinite blades. According to Wald (2006) this solution is a good estimate of the circulation distribution for the propeller blade. Strip theory calculations made with the Prandtl model show good agreement with Goldstein circulation function, especially at lower advance coefficients and larger numbers of blades (Wald 2006).

$$
\begin{aligned}
& F=\frac{2}{\pi} \cos ^{-1}[\exp (-f)] \\
& f=\frac{B}{2} \frac{R-r}{r \sin \phi}
\end{aligned}
$$

The parameters $\lambda_{1}$ and $\lambda_{2}$, shown in Equations (2) and (3) are obtained from lift and drag forces acting on a blade section, as shown in Figure 2, and correspond to the resultant of the normal and tangential forces, normalized by the term $1 / 2 \rho A W^{2}$.

$$
\begin{aligned}
& \lambda_{1}=C_{L} \cos \phi-C_{D} \sin \phi \\
& \lambda_{2}=C_{L} \sin \phi+C_{D} \cos \phi
\end{aligned}
$$

In this case, $r$ is the radial position along the blade, $\Omega$ is the angular speed of the propeller, $W$ is the relative speed on the blade, $\alpha$ is the angle of incidence (or angle of attack), $\theta$ is the

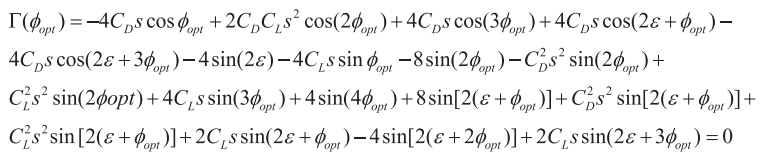

twist angle of propeller blade (or geometric pitch angle). The maximum efficiency is obtained by differentiating Equation (1) in relation to the effective pitch angle $\phi$, and eliminating $a$ and $a$ using Equations (2) and (3), which yields:

The subscript $o p t$ means optimum parameter. Equation (9) is a non-linear equation in $\phi_{\mathrm{ope}}$, and can be solved using the Newton-Raphson method.

$$
\phi_{o p t}^{i+1}=\phi_{o p t}^{i}-\frac{\Gamma\left(\phi_{o p t}^{i}\right)}{\Gamma^{\prime}\left(\phi_{o p t}^{i}\right)}
$$

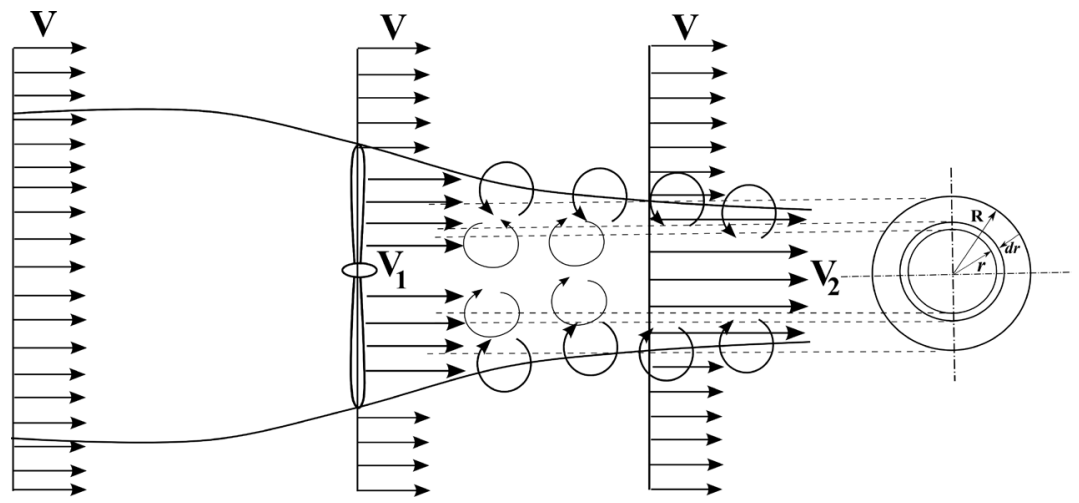

Figure 1. Control volume for an ideal propeller. 
The superscript $i$ is the index of the iterative procedure. The geometric shape of the propeller is obtained from the calculation of the chord and geometric pitch angle distributions on the blade, combining Equations (2) and (4), yields:

$$
c_{o p t}=\frac{4 \pi r}{N} \frac{a_{o p t}}{1+a_{o p t}} \frac{\left[1-\cos \left(2 \phi_{o p t}\right)\right] F}{\lambda_{1}}
$$

Usually the geometric pitch angle is obtained by the intersection of a blade by coaxial right circular cylinders of different radii (Carlton 1994). Thus, the geometric pitch angle is classically defined by:

$$
\theta=\tan ^{-1}\left(\frac{P / D}{\pi r / R}\right)
$$

where $P / D$ is the pitch ratio normalized by the diameter of the propeller, $D$. The angle of attack $\alpha$ is given by:

$$
\alpha=\theta-\phi_{o p t}=\theta-\tan ^{-1}\left[\frac{1+a_{o p t}}{x\left(1-a_{o p t}^{\prime}\right)}\right]
$$

The initial parameter of the effective pitch angle, $\phi_{0}$, used in the iterative procedure, can be obtained from velocity diagram shown in Figure 2, which is:

$$
\tan \phi_{0}=\frac{1+a_{0}}{x\left(1-a_{0}^{\prime}\right)}
$$

The subscript 0 indicates initial value for the first iteraction, and the local-speed ratio is defined as:

$$
x=\frac{\Omega r}{V}
$$

The local advance coefficient of the propeller is:

$$
J=\frac{V}{n D}=\pi \frac{r}{R} \frac{V}{\Omega r}=\frac{r}{R} \frac{1-a^{\prime}}{1+a} \tan \phi
$$

The overall thrust produced and torque absorbed by the propeller can be obtained by integrating the elementary components along the radius.

$$
T=\int_{r_{\text {boss }}}^{R} d T=\int_{r_{\text {boss }}}^{R} \frac{1}{2} \rho W^{2} B c \lambda_{1} d r
$$

$$
Q=\int_{r_{\text {boss }}}^{R} d Q=\int_{r_{\text {boss }}}^{R} \frac{1}{2} \rho W^{2} B c \lambda_{2} d r
$$

Hence, the performance coefficients are:

$$
K_{T}=\frac{T}{\rho n^{2} D^{4}}
$$

$$
K_{Q}=\frac{Q}{\rho n^{2} D^{5}}
$$

$$
\eta_{T}=\frac{J}{2 \pi} \frac{K_{T}}{K_{Q}}
$$

where $\eta_{T}$ is the total efficiency of the propeller, $K_{T}$ and $K_{Q}$ are the thrust and torque coefficients, respectively, obtained from the integration carried out along the propeller blade.

The iterative procedure for the calculation of optimum chord and geometric pitch angle at each section of the propeller blade is given as follows:

\section{Algorithm}

Require: $\Omega, \mathrm{r}, \alpha, \mathrm{C}_{\mathrm{L}}(\alpha), \mathrm{C}_{\mathrm{D}}(\alpha)$ and $\mathrm{V}$

Set initial values to $\alpha, a$ and $a$.

for $i=1$ to $N_{s}$ (Number of sections) do

Compute the initial value to $\phi_{0}$, using Equation (14);

Compute $\theta$, using Equation (12);

whileerror $>$ TOL do

iter $=$ iter +1

Compute $\lambda_{1}$ and $\lambda_{2}$, using Equations (7) and (8), respectively;

Compute $\mathrm{c}_{\text {opp }}$, using Equation (11);

Compute $\phi_{\text {opt }}$, using Equation (9), which is solved by Newton-Raphson method;

Compute $\alpha$, using Equation (13);

Compute $a_{\mathrm{opt}}$ and $a_{\mathrm{opt}}$, using Equations (2) and (3), respectively;

Compute error;

end while

\section{end for}

Compute propeller blade geometry: chord and geometric pitch angle distributions. 


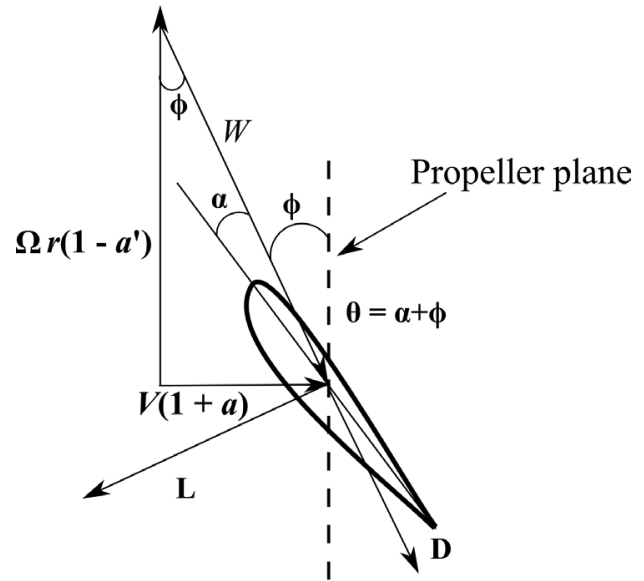

Figure 2. Velocities and forces acting on a section of the propeller blade.

\section{RESULTS}

\section{Results for the Proposed Hydrodynamic Model}

Based on the data obtained from the theory of Glauert (1935), the parameters for $r / R=0.7, s=0.1$, and $\theta=24^{\circ}$ were computed, as shown in Table 1. Figure 3 shows a comparison between the propeller efficiency obtained with the proposed model and those described by Glauert (1935). Note that for zero $\operatorname{drag}(\varepsilon=0)$, i.e. without the influence of viscous dissipation, the model converges to the result of Glauert (1935) (Figure $3 A)$. The increase of the viscous dissipation $(\varepsilon>0)$ promotes a significant decrease of the propeller local efficiency. This effect was predicted by Glauert (1935) and other classical authors in the literature, such as Carlton (1994). In the present methodology, this loss is predicted through the hydrodynamic characteristics of the hydrofoil, which can be obtained from experimental survey or numerical simulation (Wu et al. 2015; Drela 1990). Therefore, these results indicate that the proposed method has physical consistency. The value of $\varepsilon>0$ was omitted in the work developed by Glauert (1935). The optimal effective pitch angle is obtained by equation (10), which is calculated using Newton-Raphson's method applied in Equation (9). The behavior of the optimization method is depicted in Figure $3 \mathrm{~B}$. It can be observed that the method always converges to the maximum efficiency for any $\varepsilon$. Table 2 presents optimal results for the proposed method. Note that viscous dissipation has a strong influence on the propeller efficiency. Equation (1) shows the efficiency behavior as a function of $\varepsilon$. In other words, the curve of efficiency decreases when the viscous dissipation increases, and the maximum point on the curve becomes well defined.

\section{Comparison with the B3-50 Propeller}

Here, a comparison with the open-water characteristics of the 3-bladed Wageningen B-series propeller (Troost 1951; Lammeren et al. 1969) is carried out. Having a blade-area ratio of 0.5 , this propeller geometry corresponds to the pitch ratio $\mathrm{P} / \mathrm{D}=0.6$. Being a well known test case in the literature (Carlton 1994), the Wageningen series was chosen. Its behavior has been extensively studied in the past, and it is currently representative of general purpose fixed-pitch propeller design. The performances of the Wageningen propellers were calculated using the polynomials provided by Oosterveld and Oossanen (1975), which are based on accurate regression analyses from experimental data on propeller models. Rotational speed was fixed at $331 \mathrm{rpm}$, while the undisturbed flow velocity $V$ was varied to obtain different values of the advance coefficient $J$. The blades' geometries are depicted in Table 3. For the proposed model, the same operation conditions of the Wageningen B3-50 was considered. Figure 4 reports the comparison between the experimental data and the proposed model, in which a good physical consistency is noticed.

\section{Results for small boats in the Amazon region}

In this study, a typical marine propeller is considered (Figure 5), which is normally used on small passenger boats in the Amazon region. Due to the difficulties in obtaining the detailed dimensions of the propeller, the coordinates of the propeller shape were measured using Markgraf software, written in $\mathrm{C}$ language, which provides the coordinates of the stations through scanned images. To promote a comparison with survey data, the proposed model was used to compute a propeller blade shape, considering the same features from a regional propeller. It is important to clarify that the skew angle shown in Figure 5 was considered only after the optimization procedure, since the proposed model does not consider the propeller skew effect. More over, in all simulations the time processing for the solution of the algorithm did not exceed five minutes. Figure 6 presents the blades' geometries computed for the two cases. Note that the propeller blade shown in Figure 6A presents expanded blade area ratio $\left(A_{E} / A_{0}=0.5\right)$ higher than a typical propeller, Figure 6B. This effect is detailed by Nóbrega et al. (2013), where the increase of $A_{E} / A_{0}$ increases the drag on the propeller due to the viscous effect, but avoids the cavitation effect. In this work, cavitation is not considered. However, another important aspect for an efficient marine propeller design is performed with the optimization of the propeller hydrodynamic shape. This feature constitutes a significant difference when compared with typical propeller shown in Figure 6, leading to an improvement in propeller efficiency.

The hydrofoil NACA 66206 is used, which has a good efficiency according to Favacho et al. (2014). For this hydrofoil, the Reynolds number is $2 \times 10^{6}$. The lift and drag coefficients were obtained using XFOIL, which is a coupled panel/viscous code developed at MIT (Drela 1990). XFOIL is a collection of programs for airfoil design and analysis for incompressible/compressible viscous flows over an arbitrary 
Table 1.Parameters for a blade element according to Glauert (1935).

\begin{tabular}{|c|c|c|c|c|c|c|}
\hline$\alpha\left(^{\circ}\right)$ & $\phi\left(^{\circ}\right)$ & $\lambda_{1}$ & $\lambda_{2}$ & $\mathrm{a}$ & $a^{\prime}$ & $\mathrm{J}$ \\
\hline 4 & 20 & -0.012 & 0.036 & -0.003 & 0.003 & 0.80 \\
\hline 6 & 18 & 0.204 & 0.088 & 0.056 & 0.007 & 0.67 \\
\hline 8 & 16 & 0.410 & 0.132 & 0.156 & 0.012 & 0.54 \\
\hline 10 & 14 & 0.610 & 0.164 & 0.363 & 0.017 & 0.40 \\
\hline 12 & 12 & 0.780 & 0.178 & 0.820 & 0.021 & 0.25 \\
\hline 14 & 10 & 0.964 & 0.186 & 4.000 & 0.026 & 0.08 \\
\hline 16 & 8 & 1.136 & 0.180 & -3.13 & 0.032 & -0.14 \\
\hline
\end{tabular}
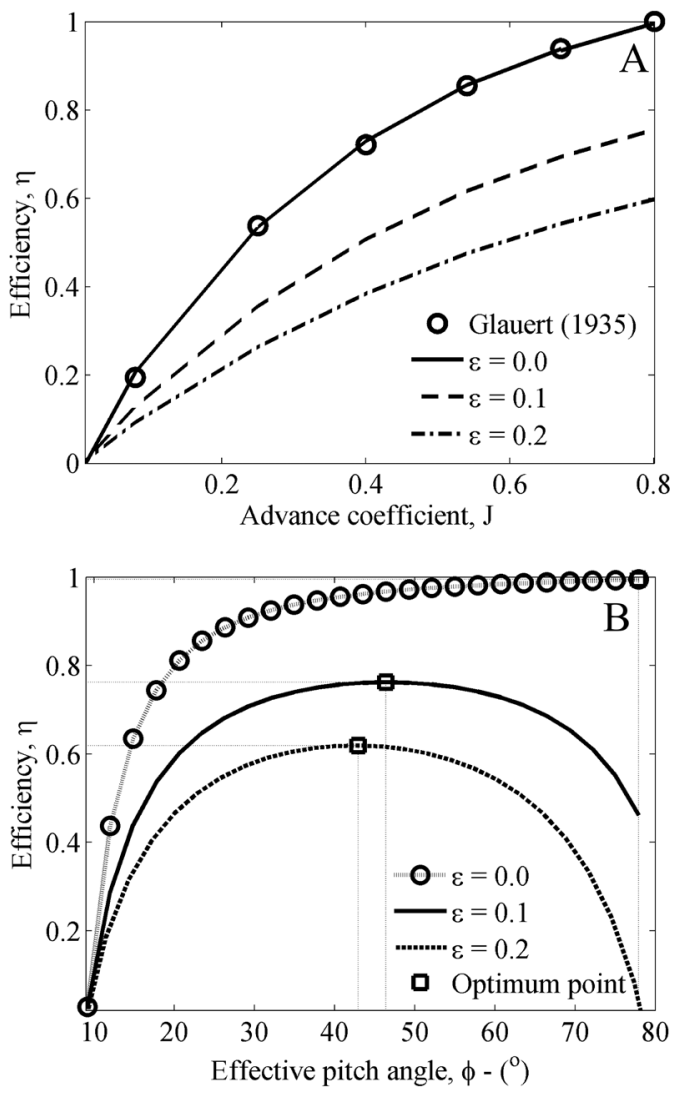

Figure 3. (A) Local efficiency as a function of the local advance coefficient. (B) Local efficiency as a function of the effective pitch angle.

Table 2. Results obtained using equations (1) and (7).

\begin{tabular}{ccc}
\hline$\varepsilon=C_{D} / C_{L}$ & $\phi_{\text {opt }}\left({ }^{\circ}\right)$ & $\eta_{\max }(\%)$ \\
\hline 0.0 & 78 & 100 \\
0.1 & 46 & 76 \\
0.2 & 43 & 62 \\
\hline
\end{tabular}

airfoil. In this code, a zonal approach is used to solve the viscous flow indirectly and an equivalent inviscid flow is postulated outside a displacement streamline that includes the viscous layer, becoming a powerful software for aerodynamic design, and presenting good agreement when compared with experimental data (Benini 2004). Figure 7 shows the lift and drag coefficients, respectively, generated using 120 panels.

Figure 8 compares the results obtained in an "open water" regime. For performance analysis of the propellers, a simple but effective BEMT was used, as mentioned previously. In this method, the propeller blade is divided into a number of elementary streamtubes (called "strips") along the radius, in which a force balance is applied involving a two-dimensional profile lift and drag along with the thrust and torque produced within the strip (Wald 2006). At the same time, a balance of axial and angular momentum is applied. According to Benini (2004), the BEMT is consistent with experimental data. Figure 8A shows improved behavior for the propeller designed in this work. It can be seen that the propeller efficiency is $59 \%$ against $45 \%$ for the typical propeller, considering the same operating conditions. The increase of the efficiency is $37 \%$ higher than the typical propeller at the rated advance velocity. The torque and thrust are very close compared to a typical propeller, as shown in Figure 8B, indicating good performance of the proposed model. However, for $J<0.5$, the torque and thrust coefficients increase, showing that the present approach provides an alternative methodology for the marine propeller design, contributing to the development of marine propeller technology in the region.

\section{DISCUSSION}

The marine propeller design in the Amazon region is generally empirical. Manuscripts or references notes, instruments or equipment that can be used with some accuracy are not available to boat builders from the region. It is important to characterize the design techniques, the mapping of empiricism practiced and, especially, the development of 
Table 3.Blade geometries of the propellers.

\begin{tabular}{|c|c|c|c|c|c|}
\hline Ns & $r / R$ & $\mathrm{c} / \mathrm{R}$ & $\theta-(\mathrm{rad})$ & $c^{*} / R$ & $\theta^{*}-(\mathrm{rad})$ \\
\hline 1 & 0.2 & 0.272 & 0.762 & 0.602 & 0.762 \\
\hline 2 & 0.3 & 0.305 & 0.567 & 0.945 & 0.567 \\
\hline 3 & 0.4 & 0.333 & 0.445 & 1.225 & 0.445 \\
\hline 4 & 0.5 & 0.353 & 0.365 & 1.335 & 0.365 \\
\hline 5 & 0.6 & 0.364 & 0.308 & 1.227 & 0.308 \\
\hline 6 & 0.7 & 0.361 & 0.264 & 0.951 & 0.266 \\
\hline 7 & 0.8 & 0.354 & 0.223 & 0.627 & 0.234 \\
\hline 8 & 0.9 & 0.276 & 0.186 & 0.356 & 0.209 \\
\hline 9 & 1.0 & 0.000 & 0.155 & 0.177 & 0.189 \\
\hline
\end{tabular}

$\left.{ }^{*}\right)$ Results obtained with the proposed model.

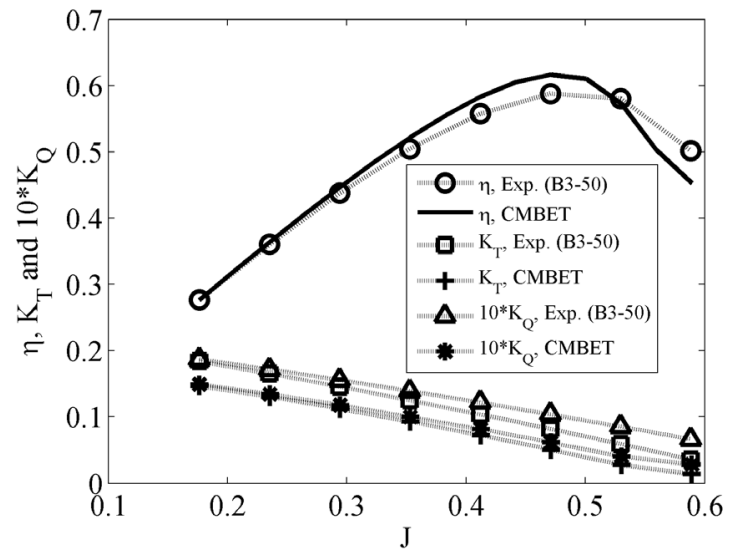

Figure 4. Propeller efficiency, thrust and torque coefficients as functions of advance coefficient.

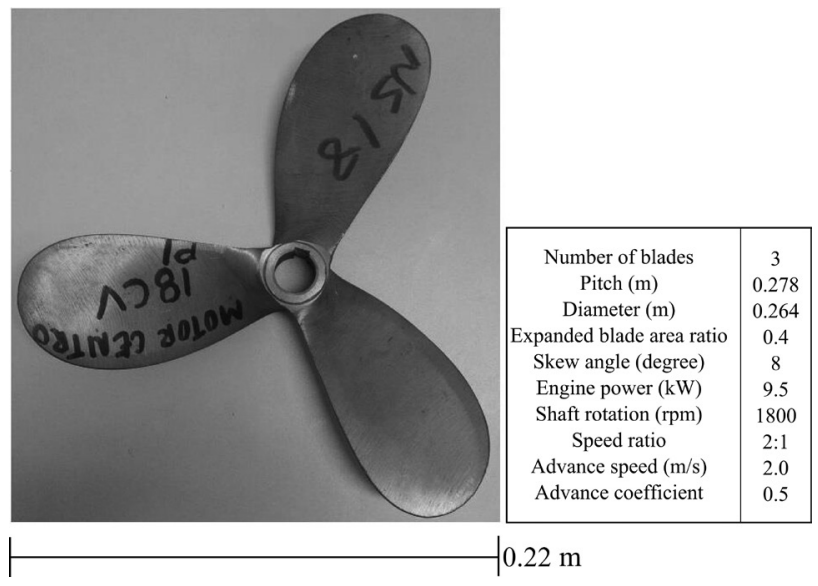

Figure 5. Details of a typical marine propeller used in the Amazon region.
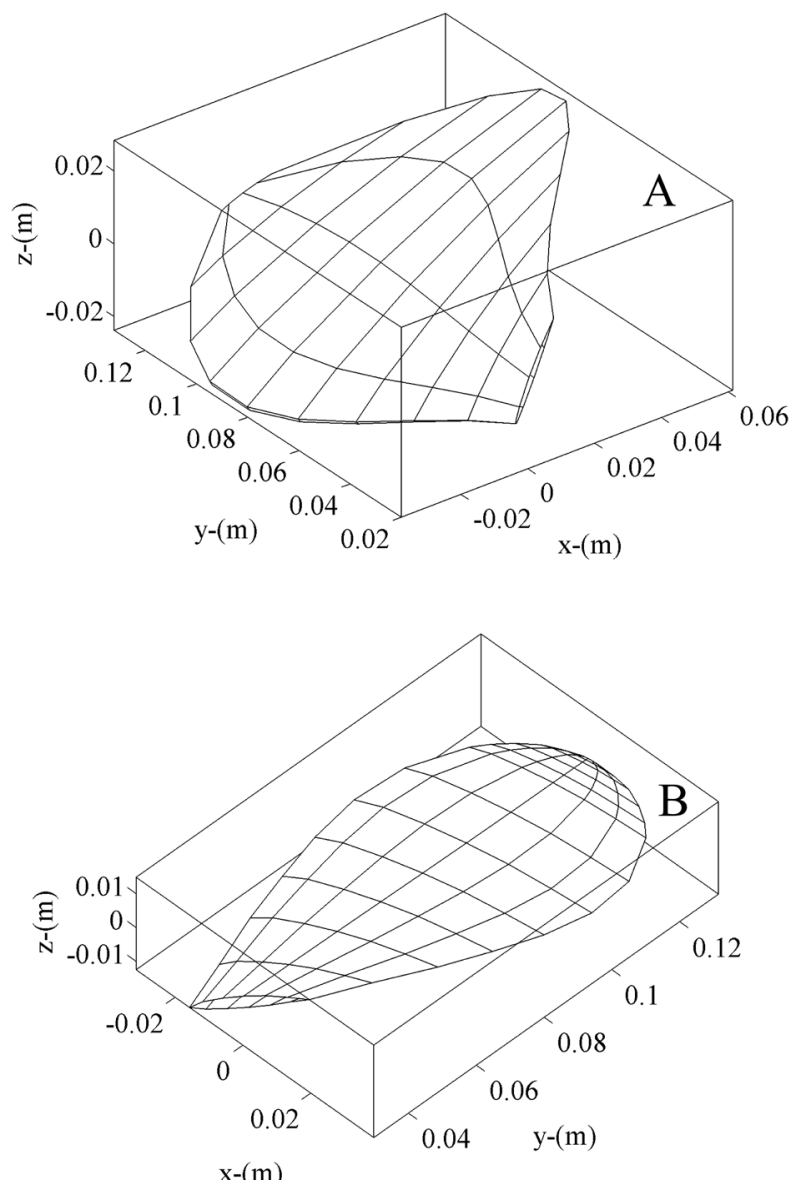

Figure 6. (A)Propeller geometry obtained using the proposed model. (B) Propeller geometry for a typical propeller used in the Amazon region. 

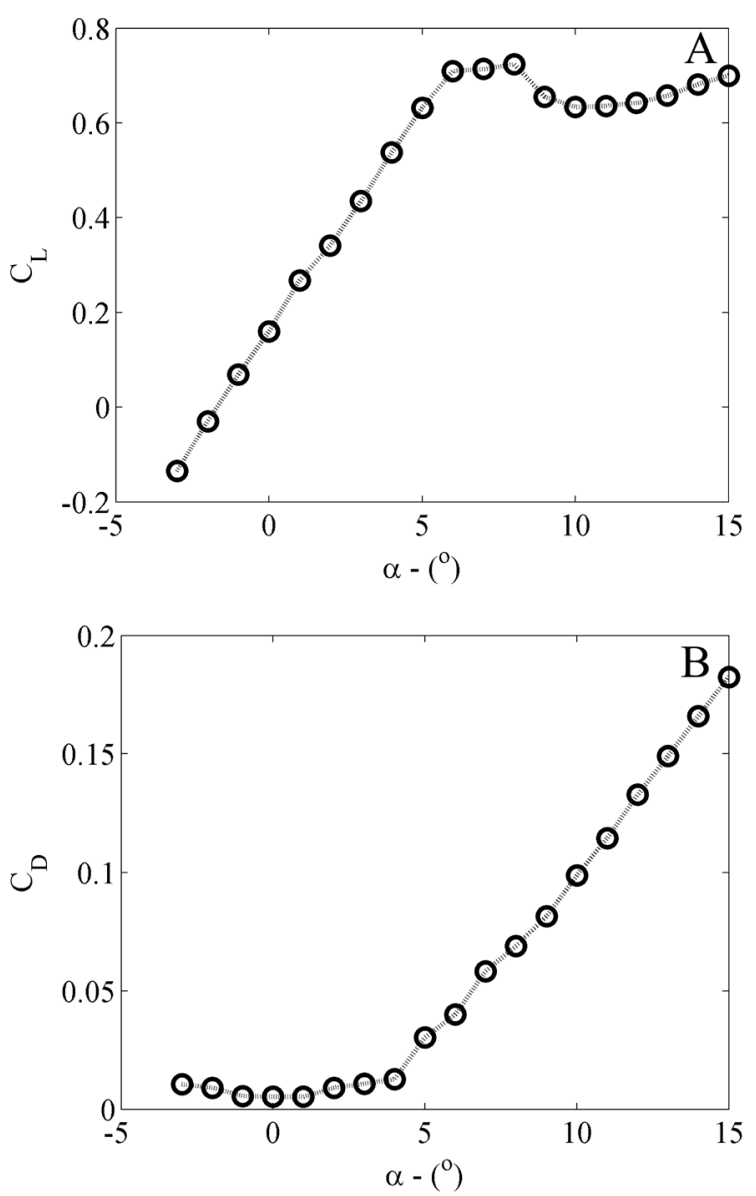

Figure 7. (A) Lift coefficient. (B) Drag coefficient.

knowledge and expertise on the hydrodynamic design of marine propeller technology. The study is original and provides promising results and technological development of current methods for the propeller design. Thus, the methodology presented in this work is an alternative approach, which is an extension of classical theory (Glauert 1935), considering the wake effects and the viscous influence on the blade propeller. The proposed method presents easy implementation and low computational processing. The results show that the mathematical model converges to the theory of Glauert (1935), presenting physical consistency when compared with the Wageningen B3-50 propeller. The propeller designed with the methodology described in this paper has good efficiency, and it constitutes an important technology to be applied in remote areas. However, there are some limitations of the proposed methodology, which need to be investigated, such as: (a) comparisons with experimental data for a detailed analysis of the proposed model behavior, (b) taking into account the cavitation effect on the propeller blade due to strong pressure variations, (c) considering the skew angle on
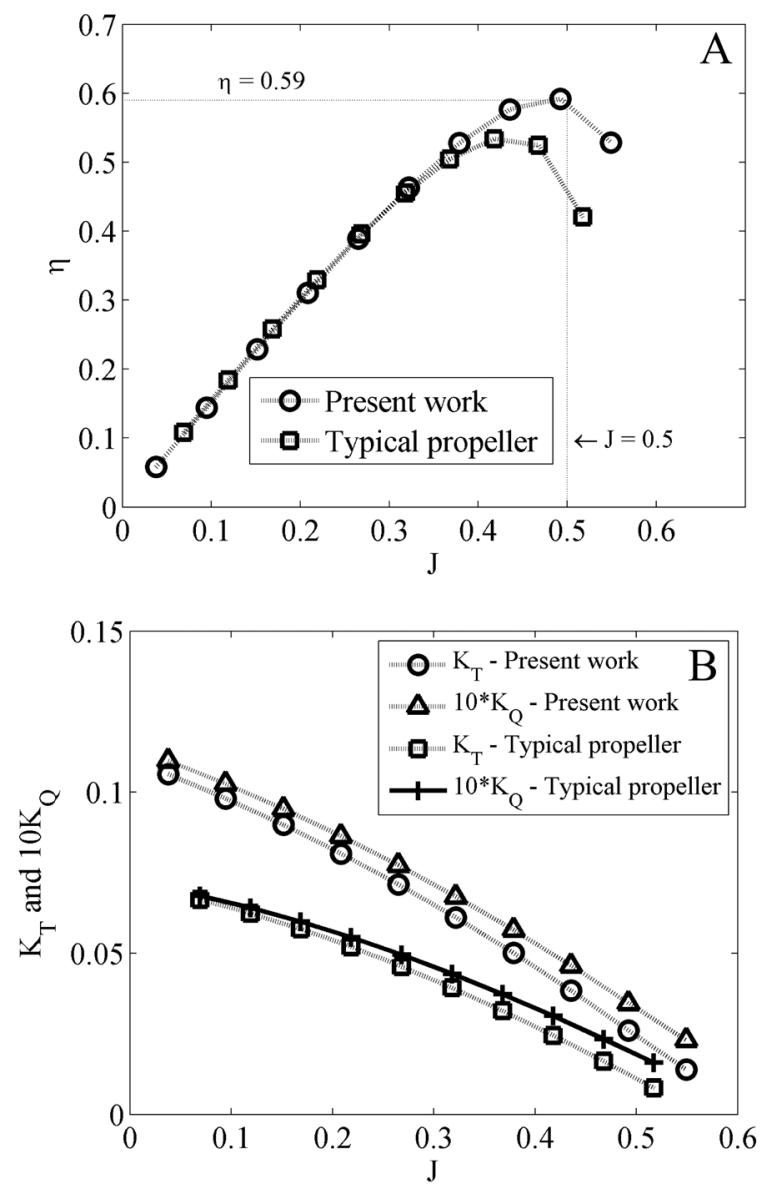

Figure 8. (A) Efficiency curves. (B) $K_{T}$ and $K_{Q}$ curves.

the propeller, which is a geometric fit that alleviates propeller induced vibrations on the shaft and hull, as well as pressure pulses at the stern as a consequence of the propeller operation in the wake field.

\section{CONCLUSIONS}

The simple and efficient methodology presented in this work constitutes an alternative tool for modest boat builders in the Amazon region. Additionally, the methodology showed easy implementation and low computational cost. The processing time was less than five minutes for all simulations, indicating that the propeller hydrodynamic design procedure is faster when compared with other expensive approaches available in the literature. The optimization technique ensures the viscous dissipation effect in its formulations, which is needed in any propeller design model. The method presents good agreement with the open-water characteristics of the 3-bladed Wageningen B-series propeller, which is usually taken into account by boat builders in Amazon region. Thus, the 
present optimization methodology can help to solve propeller hydrodynamic issues which cause damage to propellers.

\section{ACKNOWLEDGEMENTS}

The authors would like to thank the Universidade Federal do Pará (UFPA), Conselho Nacional de Desenvolvimento Científico e Tecnológico (CNPq), Coordenação de Aperfeiçoamento de Pessoal de Nível Superior (CAPES) and the Fundo Nacional de Desenvolvimento da Educação (FNDE, through the agreement 16175) for financial support. A special thanks to Debanik Bhattacharjee, University of Calgary, Alberta, Canada for technical suggestions.

\section{REFERENCES}

Benini, E. 2004. Significance of blade element theory in performance prediction of marine propellers. Ocean Engineering, 31: 957-974.

Bontempo, R.; Cardone, M.; Manna, M.; Vorraro, G. 2014. Ducted propeller flow analysis by means of a generalized actuator disk model. Energy Procedia, 45:1107-1115.

Carlton, J.S. 1994. Marine Propellers and Propulsion. ButterworthHeinemann Ltd, 1st edition, p. 544.

Costa, L.S.S. 2004. As Hidrovias nos Interiores do Brasil. Rio de Janeiro: Fenavega Editions, 3rd Edition.

Drela, M. 1990. Elements of Airfoil Design Methodology. Applied Computational Aerodynamics Progress in Astronautics and Aeronautics, 125:167-189.

Favacho, B.I.; Vaz, J.R.P., Mesquita, A.L.A. 2014. Contributions to the Marine Propellers Hydrodynamic Design. Thermal Engineering, 13:41-47.

Froude, W. 1878. On the Elementary Relation between Pitch, Slip and Propulsive Efficiency. In: Transactions, Institute of Naval Architects, 19: 47-57.

Glauert, H. 1935. Aerodynamic Theory. V. 6 Div. L, W. F. Durand, ed., Berlin: Julius Springer, 324p.
Lammeren, W.P.A.; Van Manen, J.D.; Oosterveld, M.W.C. 1969. The Wageningen B-screw series. SNAME Transactions, 77:269317.

Morgut, M.; Nobile, E. 2012. Influence of grid type and turbulence model on the numerical prediction of the flow around marine propellers working in uniform inflow. Ocean Engineering, 42:26-34.

Nóbrega, J.; Dan, T.C.; Rubanenco, I. 2013. Simple Calculation of Boat Propeller. International Journal of Engineering and Innovative Technology, 2:141-144.

Oosterveld, M.W.C.; Van Oossanen, P. 1975. Further computeranalyzed data of the Wageningen B-screw series. International Shipbuilding Progress 22:251-262.

Rankine, W.J.M. 1865. On the Mechanical Principles of the Action of Propellers. In: Transactions, Institute of Naval Architects, 6: 13-30.

Sánchez-Caja, A.; González-Adalid, A.; Pérez-Sobrino, M.; Sipilä, T. 2014. Scale effects on tip loaded propeller performance using a RANSE solver. Ocean Engineering, 88:607-617.

Takinaci, A.C.; Atlar, M. 2002. Performance assessment of a concept propulsor: the thrust-balanced propeller. Ocean Engineering, 29:129-149

Troost, L. 1951. Open-water test series with modern propeller forms. Transactions of NECIES, 67.

Wald, Q.R. 2006. The aerodynamics of propellers. Progress in Aerospace Sciences, 42: 85-128.

Wu, Q.; Huang, B.; Wang, G.; Gao, Y. 2015. Experimental and numerical investigation of hydroelastic response of a flexible hydrofoil in cavitating flow. International Journal of Multiphase Flow, 74:19-33.

Zhu, Z. 2015. Numerical study on characteristic correlation between cavitating flow and skew of ship propellers. Ocean Engineering, 99:63-71.

Recebido em 09/05/2015

Aceito em 23/07/2015 
